\title{
THE NEW ENGLAND SLEET STORM, DECEMBER 22-24, 1952
}

\author{
HARRY E. BROWN AND CHARLOTTE L. ROE
}

WBAN Analysis Center, U. S. Weather Bureau, Washington, D. C.

\section{INTRODUCTION}

Winter began with a cyclone bringing stormy weather to much of the Atlantic Coastal Region of the United States, particularly New England. A wave which originated in the Carolinas occluded off Hatteras, N. C. on December 21, 1952. For the next 2 days the occluded system moved east-northeastward and on the third day it recurved abruptly to the north. During these 3 days, New England had rain, freezing rain, sleet, snow, and strong winds which caused inconvenience and damage. Most of the precipitation was sleet which fell for 18 consecutive hours, contrary to the usual rapid transition from sleet to rain or snow.

The duration of the precipitation in New England depended primarily upon the movement of the storm. Forecasting the duration therefore hinged on the difficult problem of forecasting movement. Some aspects of the problem are examined from a synoptic viewpoint. Inspection of the entire storm behavior leads to the conclusion that blocking conditions were developing in the Atlantic.

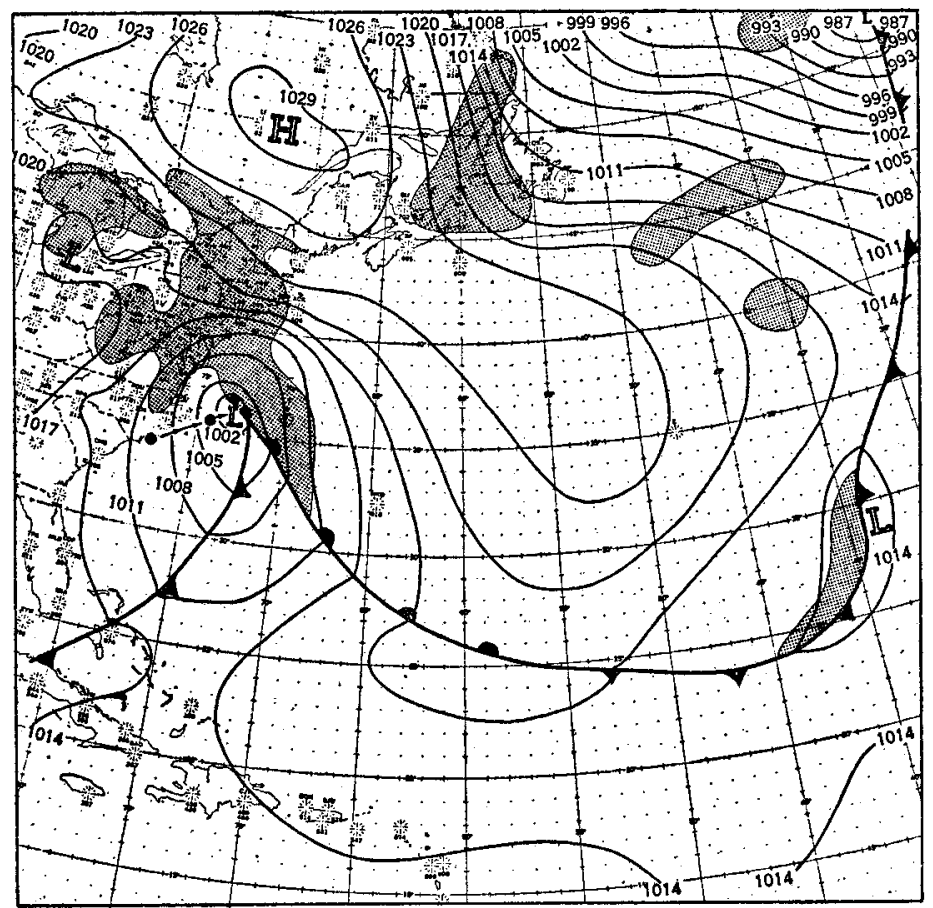

Froure 1.-Surface weather chart for $1830 \mathrm{GMT}$, December 21, 1952, as precipitation (shaded) began in southern New England. Small circles connected by arrows indicate past positions of the intensifying Atlantic coastal Low at 6-hour intervals. From these positions deceleration is apparent.

\section{DEVELOPMENT OF THE STORM}

As an occluded system moved over the Great Lakes early on December 21,1952 , a wave formed on the warm front which extended along the East Coast. This pattern, a typical example of Miller's type B East Coast cyclogenesis [1], continued to develop according to the Miller model. The old center over the Lakes filled as the new Low deepened. By 1830 GMT, December 21 (fig. 1), little circulation remained of the original surface Low and the old occluded frontal system was completely gone; the new Low gained a strong circulation, and the frontal wave occluded.

Until 1500 GMT, December 21, the mid-troposphere, e. g. at $500 \mathrm{mb}$., was changing uniformly. For the most part, the $500-\mathrm{mb}$. wave pattern was translated simply, with the isotherms remaining in phase with the contours and with both sets of isopleths remaining unchanged. The cold, short, wave trough originally associated with the old surface Low moved rapidly and regularly to the Appalachians where it influenced the development of the secondary surface Low. But by 1500 GMT (fig. 2) the $500-\mathrm{mb}$. wave pattern became asymmetrical and the trough associated with the new surface Low assumed a northwest-southeast tilt.

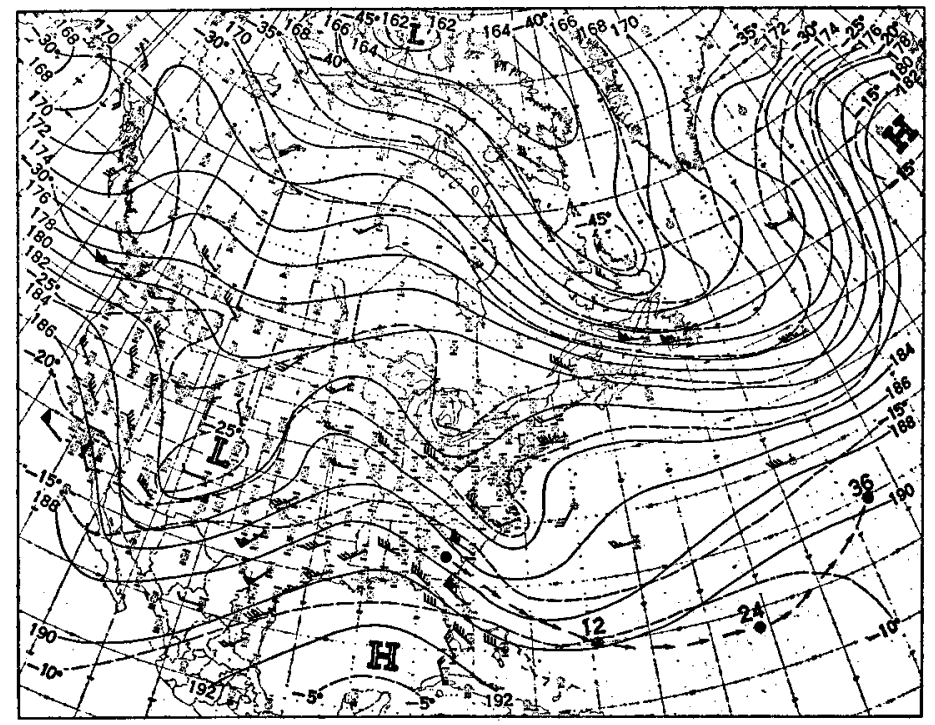

Frave 2, $-500-\mathrm{mb}$. chart for $1500 \mathrm{GMT}$, December 21, 1952. Arrows indicate constant vorticity trajectory. Numbers show position at end of 12,24 , and 36 hours. Contours (solid lines) are labeled in hundreds of geopotential feet. Isotherms (dashed lines) arein ${ }^{\circ} \mathrm{O}$. 


\section{MOVEMENT OF THE STORM}

The duration of the precipitation over New England was only slightly prolonged by the small increase in the intensity of the storm. This intensification was indicated only by the increase in the number of isobars around the Low as the central pressure remained the same.

Far more important than the effect of intensity-at least to the extent that intensification and movement are independent-was the failure of the storm to move rapidly away from New England. The direction of movement after 1830 GMT, December 21, was eastnortheast, the same as for the previous 12 hours. Not only did the direction agree with extrapolation but it remained the most probable direction as given by Miller's chart [1] of frequencies of movement for East Coast cyclones. This direction would have taken the storm away from New England if the storm had not rapidly decelerated. Deceleration from 30 knots to 12 knots was apparent on the 1830 GMT, December 21, surface chart (fig. 1) although the slowdown was not apparent in the upper air $3 \frac{1}{2}$ hours earlier. The speed was not extrapolatable and for the next 48 hours averaged 8 knots, while from the same chart of Miller's as above, 22 knots was the most probable speed. Thus, the problem of forecasting the duration of precipitation resolved itself into forecasting the speed of the storm.

As extrapolation often fails, a comprehensive understanding of the behavior of cyclones is needed, even, as in this case, to forecast a single element, speed. Because there is no such complete theory, the synoptic meteorologist must seek clues to the solution of the problem of speed by investigating such influences as blocking, conservation of vorticity, and thermal field. Some of the clues yielded by investigation of the December storm are discussed in this section.

During November 1952, a significant feature of the general circulation in the Atlantic had been a blocking condition [2,3]. Namias [4] states that a low index feature (such as blocking) is apt to repeat in the same fashion in the same season. The possibility that the blocking feature had repeated by 1500 GMT, December 21 (fig. 2) so that by this time a block might have existed to the east of the storm, therefore was investigated. Criteria for a block, in a form that can be used in conjunction with synoptic charts, are given by Rex [5]. He considers blocking to be initiated whenever the basic westerly current splits into two branches with one branch turning northward and the other branch turning southward. Over the western Atlantic the flow at $500 \mathrm{mb}, 1500$ GMT, December 21, did not conform to this pattern, therefore a block was not considered apparent. As Rex's definition came from a study of blocking in the eastern Atlantic there was the possibility that it might not be equally valid in the western Atlantic. A less restrictive definition by Elliott and Smith [6] states that when block- ing exists temperatures and pressures in the blocking ridge are considerably above normal. The five-day mean 700-mb. height departure from normal, for the period December 17-21 (fig. 3), as drawn by the Weather Bureau's Extended Forecast Section, shows that the heights to the east of the storm were near or below normal. Thus, the presence of blocking in this situation was not indicated by the criteria of either Rex or Elliott and Smith, and therefore deceleration of the storm due to blocking could not be assumed.

If the speed of the $500-\mathrm{mb}$. trough associated with the storm could have been forecasted then the speed of the surface Low would have followed assuming that the association remained nearly the same. Petterssen's formula [7] for determining the speed of waves, including short waves, at $500 \mathrm{mb}$. was not applicable to this case.

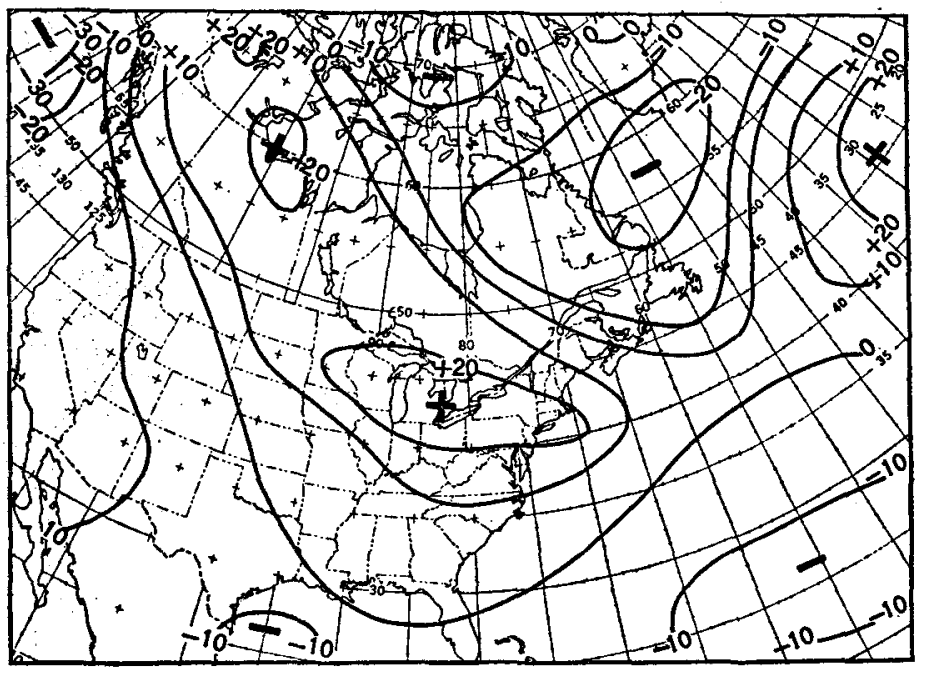

Figure 3,-700-mb, height departure from normal for the period December 17-21, 1952 Note near and below normal heights (labeled in tens of feet) to east of storm area. Chart prepared by Extended Forecast Section, U. 8. Weather Bureau.

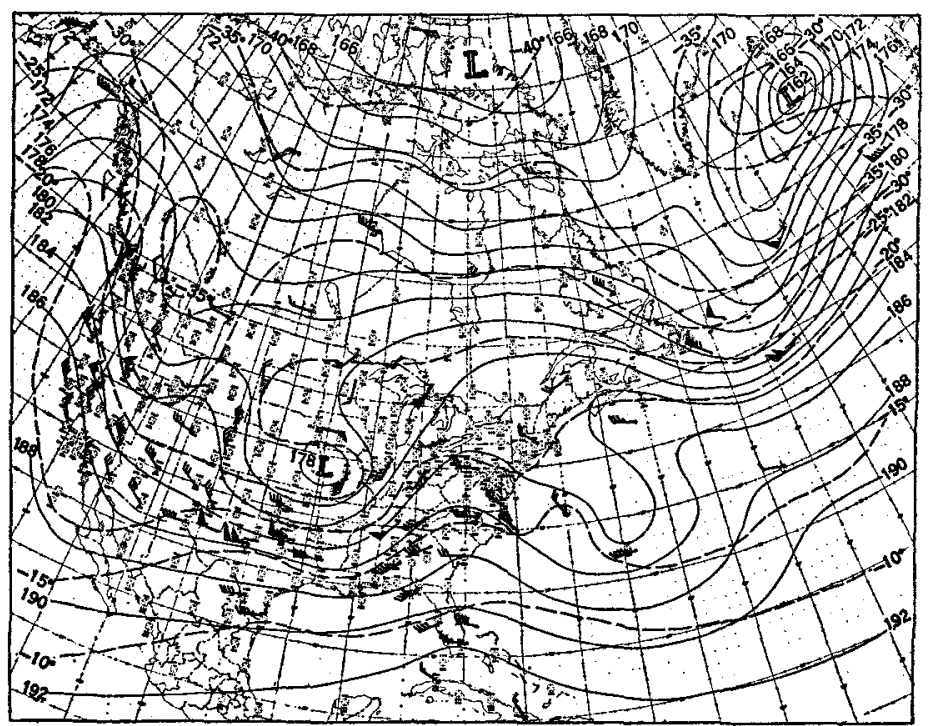

FIGURE 4.-500-mb, chart for $1500 \mathrm{GMT}$, December 22, 1952. Compare contour directions at corresponding points on the constant vorticity trajectory shown on figure 2. 
A condition for the use of the formula is that the wave be symmetrical, but this wave was asymmetrical by the time of deceleration of the surface Low. The formula is based on the conservation of vorticity. This principle of course may be applied to construct constant vorticity trajectories, as described in Rossby [8], and thus to obtain trough movements. The analyzer developed by Wobus [9] was used to make such a trajectory on the 1500 GMT, December 21, 500-mb. chart (fig. 2). The result shows that the southern portion of the trough would be expected to continue moving rapidly eastward. This can be verified by checking the direction of the contour at the same location on the 1500 GMT, December 22, 500-mb. chart (fig. 4). No constant vorticity trajectory seemed to indicate a slow movement of the northern portion of the trough.

So far at $500 \mathrm{mb}$. only the wind field as represented by contours has been considered but the temperature field should be considered as well. The temperature analysis suggested the use of the 1000-500 mb. thickness (mean isotherms) which is the primary synoptic tool of Sutcliffe [10]. From a comparison of his selected patterns with the pattern of the thickness lines for 1500 GMT, December 21 (fig. 5), it appeared that the thermal trough of this storm was an example of "the cyclonic thermal involution." Of this type Sutcliffe states that the reversed thermal over the cyclonic region is not in harmony with wave-like thermal steering and the situation is liable to evolve further with little movement. Moreover it appeared that the

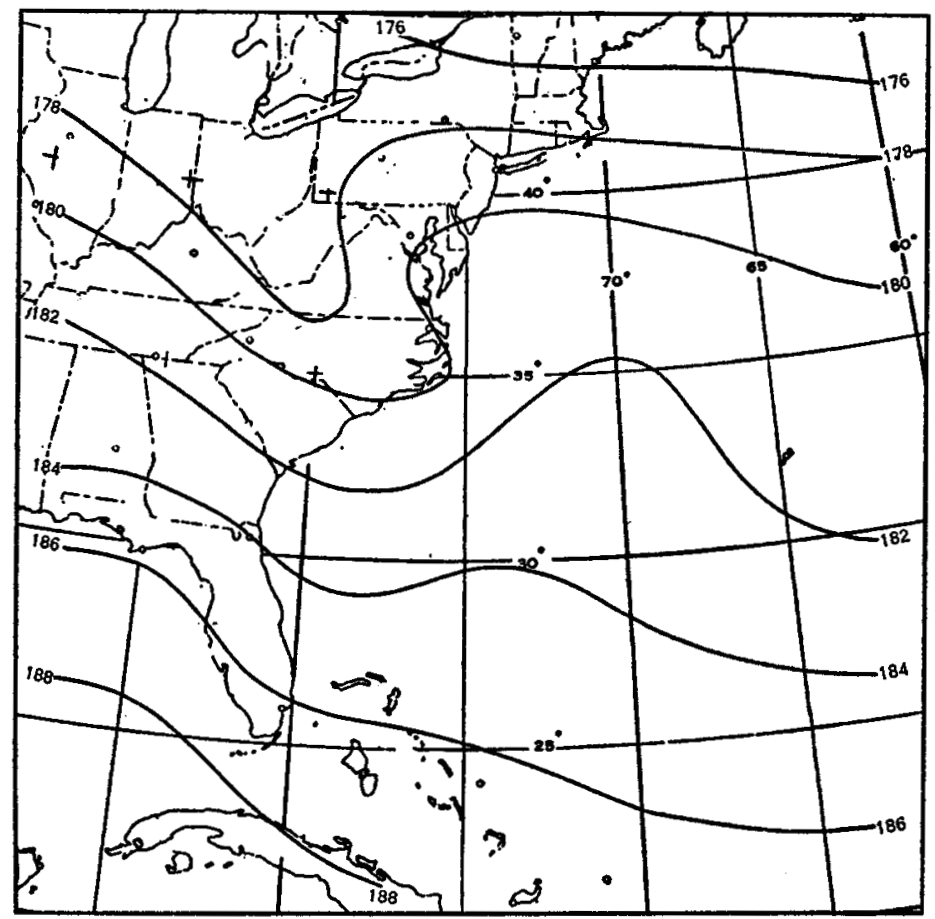

FIGURR 5. -1000-500 mb. thickness chart for $1500 \mathrm{GMT}$, December 21, 1952. Thickness, labeled in hundreds of feet, is proportional to mean virtual temperature. The thermal trough is an example of "the cyclonic thermal involution" and the thermal ridge east of the trough is an example of "the difluent thermal ridge" described by Sutcliffe [10]. attendant thermal ridge east of the trough was an example of "the difluent thermal ridge," of which he states that with weak thermals ahead there is little tendency for pressure systems to break and run through the pattern. From these considerations the storm might have been expected to move slowly.

Next, George's objective method [11] for obtaining a quantitative forecast of the speed of surface Lows was tried. The method combines wind and thermal effects and characteristics of the upper level trough. Computations made from graphs in his Report No. 2 by using data from 1500 GMT upper level charts and $1830 \mathrm{GMT}$ surface charts of December 21 gave a forecast speed of 22 knots for the next 24 hours. This forecast speed happens to be

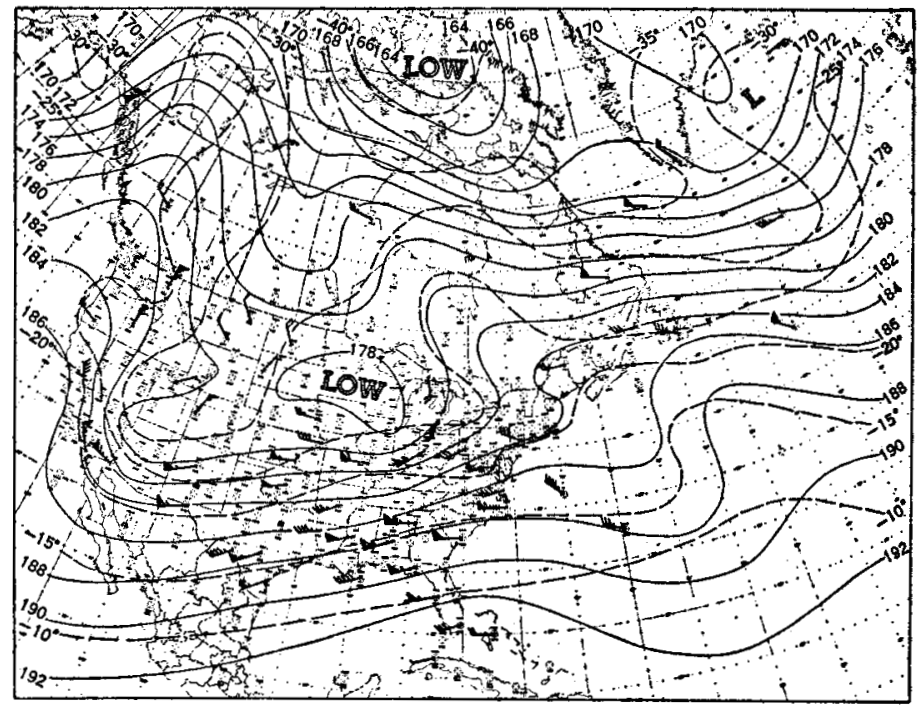

Figure 6.-500-mb. chart for $1500 \mathrm{GMT}$, December 23, 1952. Note intensification of ridge to east of trough and change in westerlies to single band over Labrador and the western Atlantic. Compare with figures 2 and 4.

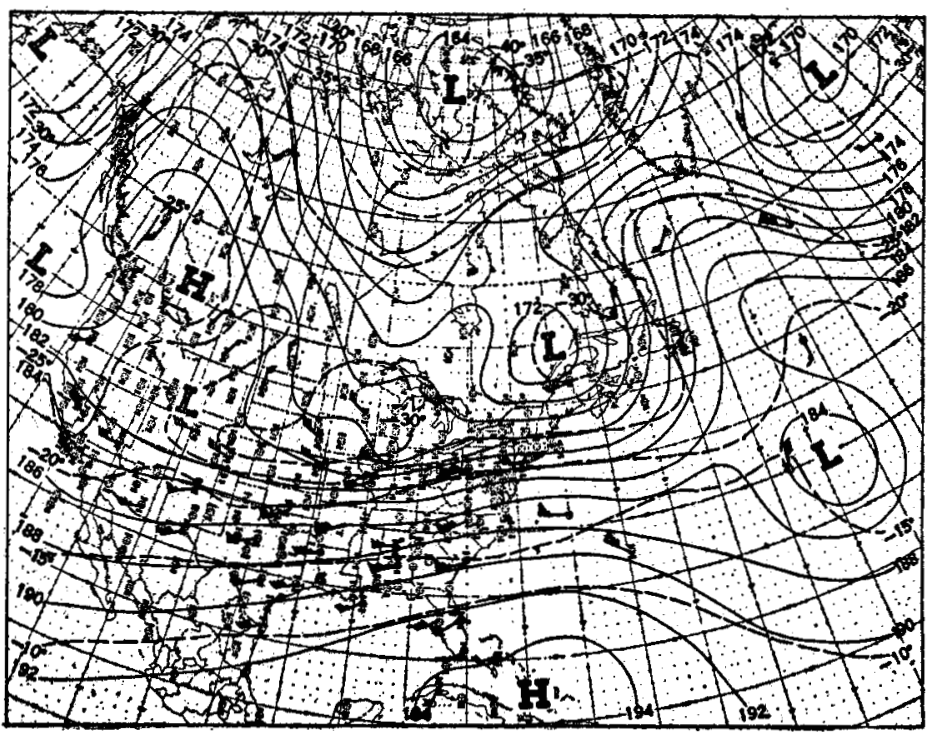

Figure 7. $-500-m b$. chart for 1500 GMT, December 25, 1952. Ridge now resembles fourth or blocking stage in the "index cycle" described by Namias and Clapp [12]. 
the same as the past speed of the 500-mb. trough. The speed of the surface Low observed for the six hours before 1830 GMT, December 21, was already only 12 knots. In Report No. 3 George says that for upper level troughs described as "slow" or "stationary steepening" the speed of the Low at the surface would be one half the value given in Report No. 2. Only from the comparison with Sutcliffe's selected patterns, however, might the trough have been described as "slow" for it had not yet shown any deceleration. The use of the correction indicated in Report No. 3 gave a forecast speed of 11 knots, obviously much closer to the observed speed of 8 knots for the next 24 hours.

After the storm's deceleration, characteristics appeared in the circulation which indicated that blocking conditions in the western Atlantic might be forming. On December 23 (fig. 6) the 500-mb. ridge to the east of the East Coast trough had been reinforced by a faster moving ridge from Canada (compare figs. 2, 4, and 6). The westerlies over North America, which had been split into two wave trains in different latitude bands (figs. 2 and 4), now appeared in one band over Labrador and the western Atlantic. Namias and Clapp [12] observed that when the westerlies change in this manner they often go through a complete "index cycle". Figure 6 conforms to stage two of the "index cycle" they describe. Figure 7, 1500 GMT, December 25, resembles the fourth stage characterized as blocking.

The easternmost point along the east-northeast track was reached by the storm at 1830 GMT, December 23

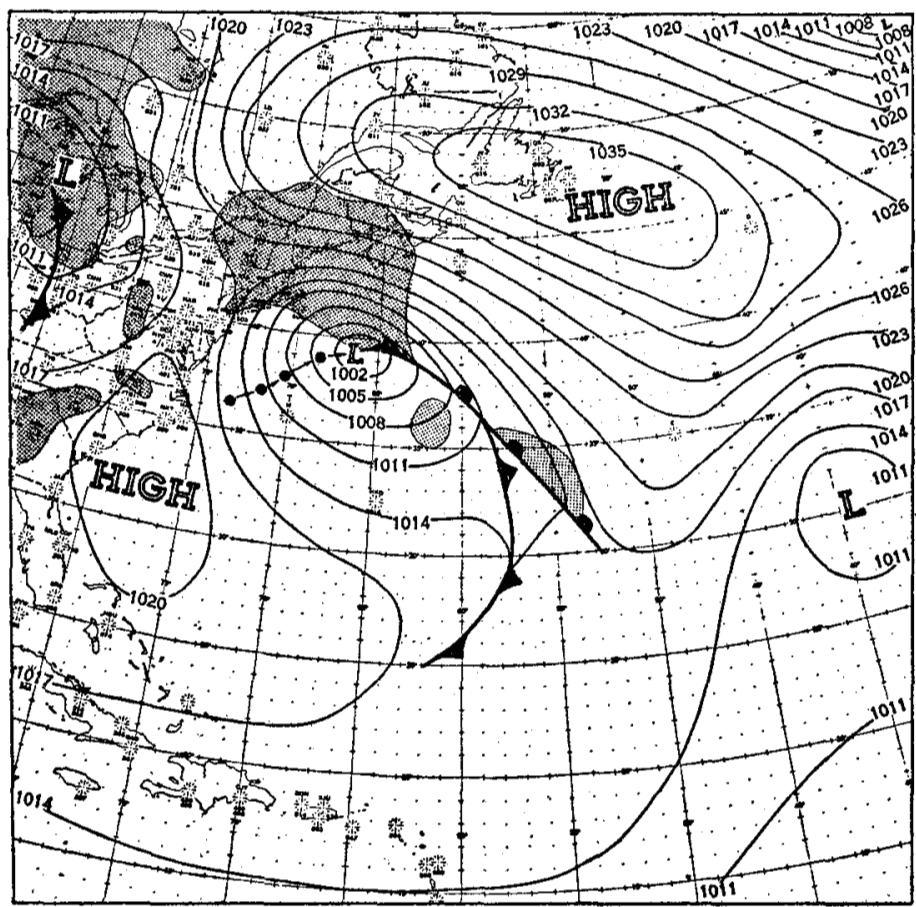

Figure 8. - Surface weather chart for 1830 GMT, December 23, 1952 . Small circles connected by arrows indicate past positions of the main Low at 12-hour intervals. This was the farthest-east position reached by the storm. (fig. 8). Thereafter, the storm track changed abruptly to the north and the storm accelerated (see fig. 9). The $500-\mathrm{mb}$. chart nearest to the time of recurvature, 1500 GMT, December 23 (fig. 6) shows that the trough associated with the storm had joined with a Low from the west. The trough rotated northward around the $500-\mathrm{mb}$. Low and the surface storm also moved northward. [On the surface chart at the time of recurvature (fig. 8) this Fujiwhara effect [13] is not obvious, in fact it might have been expected that the storm in the East, being deeper than the Low in the Midwest, would steer the Midwest Low southward.] Soon after the old trough and the new Low combined, the Low deepened greatly as seen on the 1500 GMT, December 25, 500-mb. chart (fig. 7). With the deepening, the strength of southerly flow over the surface Low off the East Coast increased and the storm accelerated. Soon after the recurvature and acceleration the precipitation from the storm ended over all but extreme northern New England.

The entire movement (the deceleration, slow motion, recurvature, and acceleration) was one part of the start of blocking conditions in the western Atlantic. On the 500-mb. chart for 1500 GMT, December 25 (fig. 7), Rex's criteria for a block are met, and for the period December 20-24, the 700-mb. height departure from normal chart (fig. 10) showed that heights were above normal off the East Coast, in agreement with Elliott and Smith's criteria. The block persisted the rest of the month and influenced the behavior of succeeding storms. ${ }^{1}$

\footnotetext{
i see preceding article by Hawkins.
}

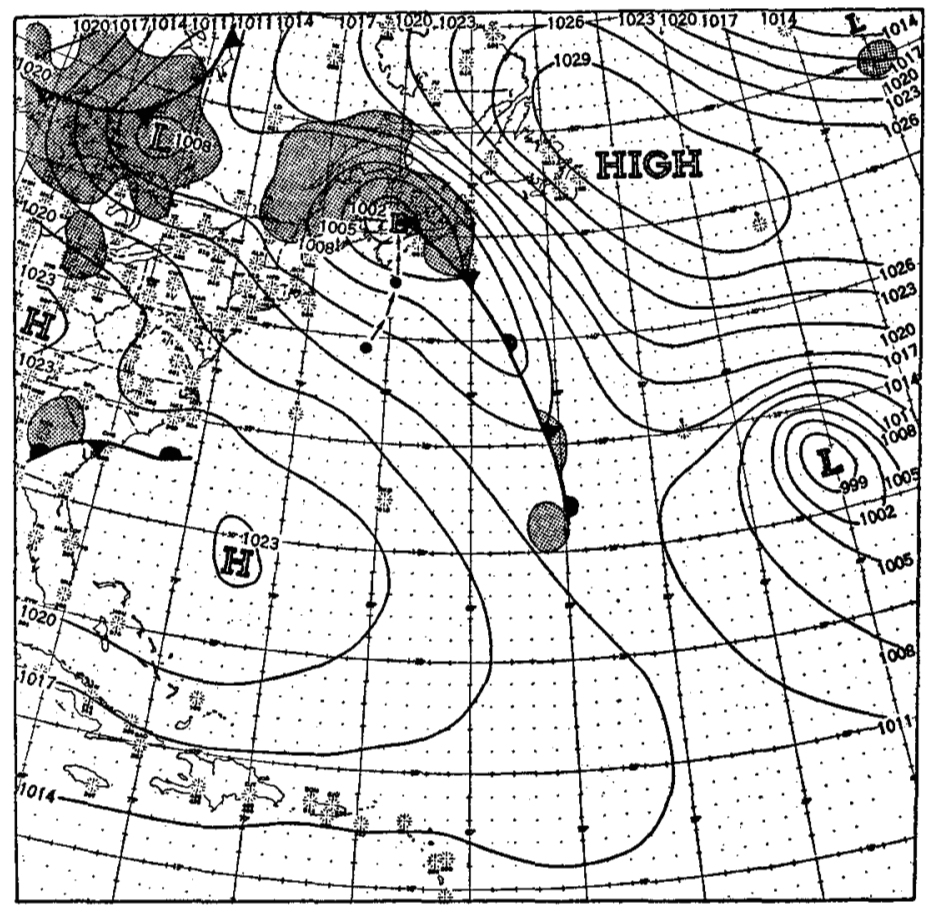

FigURe 9. - Surface weather chart for $1830 \mathrm{GMT}$, December 24, 1952 . Small circles connected by arrows indicate past positions of main Low at 12-hour intervals. Storm is now moving northward at an accelerated speed. 


\section{ASSOCIATED WEATHER CONDITIONS}

A variety of weather conditions were associated with this Atlantic coastal storm but sleet was the most striking. The precipitation began predominantly as rain in the Carolinas and moved northward into New York State and New England where it remained for approximately 48 hours. For 18 consecutive hours sleet mixed with snow, rain, and freezing rain fell at Augusta, Maine. Boston, Mass., reported sleet for 15 consecutive hours. Similar conditions were prevalent throughout New England. Airway hourly sequences indicated that fog, drizzle, freezing drizzle, and occasional snow pellets and snow grains also appeared mixed with the sleet. The precipitation was accompanied by strong winds along the coast.

A surface layer of cold air covered New England as the storm moved northward. Surface temperatures were relatively cold with Nitchequon, Quebec, on the north side of the High, reporting $-1^{\circ} \mathrm{F}$. while Caribou, Maine was the coldest reporting spot in the United States with a maximum of $19^{\circ} \mathrm{F}$. and $16^{\circ} \mathrm{F}$. respectively for December 21 and 22. The surface temperatures in the area hovered around freezing except right along the coast at such places as Nantucket, Mass. Temperature conditions aloft are illustrated by figure 11 which shows the upper air soundings for Portland, Maine for 1500 GMT, December $22,23,24$. The first sounding was taken about 7 hours prior to the snow, the second sounding was taken about 12 hours after the sleet began, and the third sounding about 3 hours following the end of the precipitation at that station. The changes of the upper air temperatures show why snow aloft changed to rain aloft. Sleet formed as the raindrops froze in falling through the cold layer of air near the surface of the earth. As these conditions

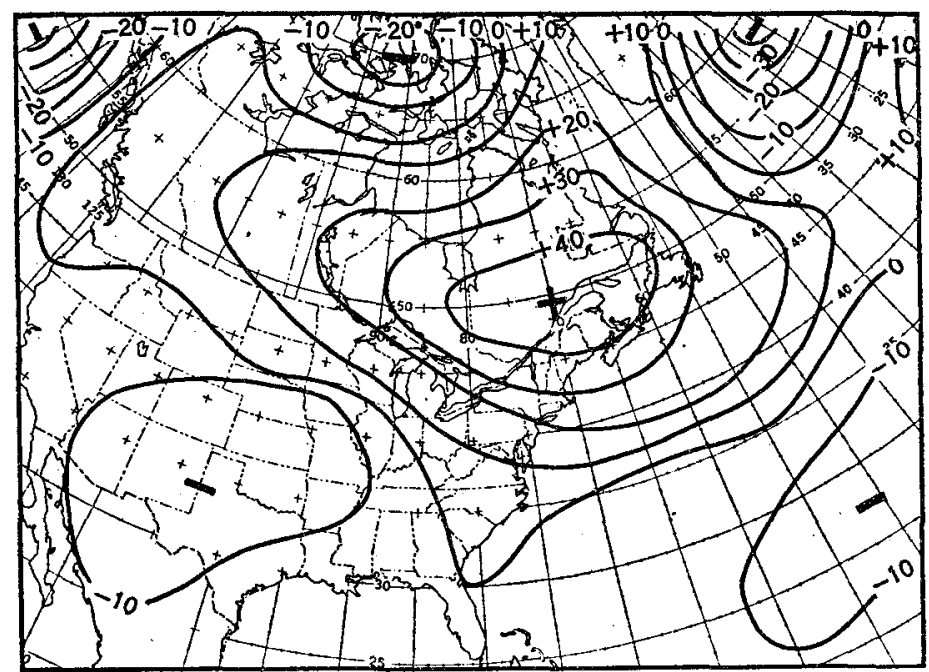

FIGURE 10.-700-mb. height departure from normal for the period December 20-24, 1952 covering the time of the storm in New England. Note the above normal heights over eastern Canada and the western Atlantic and compare with figure 3. Chart prepared by Extended Forecast Section, U, S. Weather Bureau. existed over a relatively large area, sleet was widespread, extending from Allentown, Pa., to Syracuse, N. Y., eastward over New England and northward to Caribou, Maine.

In spite of the prolonged and widespread precipitation, damage was not extensive because the amounts were not excessive. Much inconvenience was caused by the accumulation of more than 1 inch of sleet on the ground during 10 to 18 hours. Portland, Maine reported a severe ice storm on the $23 \mathrm{~d}$ that put many power and telephone lines out of action for several days. Nantucket, Mass., although reporting no sleet, did report 2.48 in. of precipitation for the period December 22-23, the greatest 24-hour amount for the month. A total of 4 inches of snow fell in parts of southern New England and mountainous areas but changed rapidly to rain and sleet.

\section{REFERENCES}

1. J. E. Miller, "Cyclogenesis in the Atlantic Coastal Region of the United States," Journal of Meteorology, vol. 3, No. 2, June 1946, pp. 31-44.

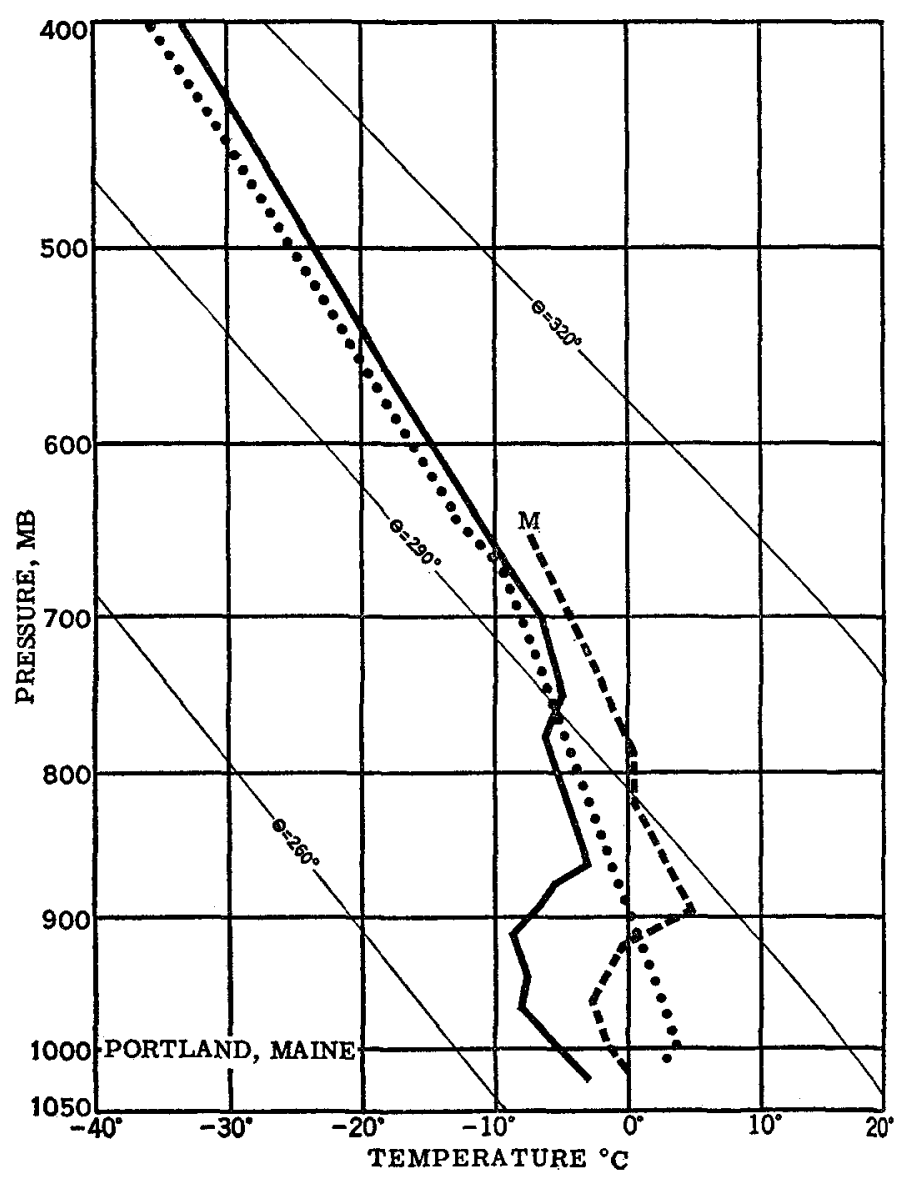

Figure 11.-Upper air soundings over Portland, Maine at 1500 GMT, December 22 (solid line), December 23 (dashed line), and December 24 (dotted line). The temperature changes show why snow aloft soon changed to rain aloft then froze as sleet while passing through the layer of cold air near the surface. 
2. Harry F. Hawkins, Jr., "The Weather and Circulation of November 1952-A Pronounced Reversal from October", Monthly Weather Review, vol. 80, No. 11, November 1952, pp. 220-226.

3. C. D. Smith, Jr. and C. L. Roe, "Comparisons Between the Storms of November 20-22, 1952 and November 25-27, 1950," Monthly Weather Review, vol. 80, No. 11, November 1952, pp. 227-231.

4. J. Namias, Extended Forecasting by Mean Circulation Methods, U.S. Weather Bureau, Washington, D. C., February 1947, p. 16.

5. D. F. Rex, "Blocking Action in the Middle Troposphere and Its Effect upon Regional Climate, I. An Aerological Study of Blocking Action", Tellus, vol. 2, No. 3, August 1950, pp. 196-211.

6. R. D. Elliott and T. B. Smith, "A Study of the Effects of Large Blocking Highs on the General Circulation in the Northern-Hemisphere Westerlies", Journal of Meteorology, vol. 6, No. 2, April 1949, pp. $67-85$.

7. S. Petterssen, "On the Propagation and Growth of Jet-stream Waves," Quarterly Journal of the Royal Meteorological Society, vol. 78, No. 337, July 1952, pp. 337-353.

8. C.-G. Rossby et al., "Forecasting of Flow Patterns in the Free Atmosphere by a Trajectory Method", Appendix to V. P. Starr, Basic Principles of Weather Forecasting, Harper and Bros., New York, 1942, pp. 268-281.

9. H. B. Wobus, Design of Differential Analyzer, U. S. Weather Bureau, Washington, D. C., 1950. (Unpublished)

10. R. C. Sutcliffe and A. G. Forsdyke, "The Theory and Use of Upper Air Thickness Patterns in Forecasting", Quarterly Journal of the Royal Meteorological Society, vol. 76, No. 328, April 1950, pp. 189-217.

11. J. J. George et al., "On the Relationship Between the Fields of Atmospheric Pressure and Temperature at Upper Levels and the Behavior of Surface Pressure Systems", Meteorology Department, Eastern Airlines, Inc., Atlanta, Ga., Report No. 2, September 1951 and Report No. 3, December 1951.

12. J. Namias and P. F. Clapp, "Observational Studies of General Circulation Patterns", Compendium of Meteorology, American Meterological Society, Boston, Mass., 1951, pp. 551-567.

13. S. Fujiwhara, "On the Growth and Decay of Vortical Systems", Quarterly Journal of the Royal Meteorological Society, vol. 49, No. 206, April 1923, pp. 75-104. 